\title{
Анализ экономической и организационной сущности современных форм финансового предпринимательства
}

\author{
Котляров И.Д. ${ }^{22}$
}

Анализ экономической, финансово-кредитной и организаџионной сущзности лизинга, факторинга и форфейтинга позволяет выявить наличие аутсорсинговой составляющей у этих видов финансового предпринимательства. Введено понятие посреднического финансирования. Выполнен сравнительный анализ этих инструментов ведения бизнеса. Приведен список видов рисков, характерных для компаний, оказывающих данные услуги.

\section{JEL: L240}

Ключевые слова: лизинг, факторинг, форфейтинг, аутсорсинг, банковский кредит, коммерческий кредит

\section{Введение}

Потребность в повышении эффективности предпринимательской деятельности привела к появлению и активному использованию на практике ряда принципиально новых, ранее неизвестных инструментов ведения бизнеса (на основе которых впоследствии возникают особые формы предпринимательства). При этом зачастую широкое внедрение таких инструментов в хозяйственную деятельность не сопровождается их адекватным теоретическим осмыслением. Лизинг, факторинг и форфейтинг не стали исключением.

В настоящее время наработана большая практика применения этих инструментов, в ряде случаев разработана соответствующая законодательная база. Есть ряд пособий, посвященных их эффективному использованию (в том числе и на русском языке); кроме того, по проблематике, связанной с этими формами ведения бизнеса, в нашей стране уже выполнено и продолжает выполняться множество диссертационных исследований (как кандидатского, так и докторского уровня). Однако все эти работы имеют ярко выраженный прикладной характер [Ачкасов, 1994; Бабичев, Лабзенко, Подлеснова, 2010; Кирилловых, 2009] и призваны в конечном счете помочь либо фирмам в эффективном применении этих инструментов в своей хозяйственной деятельности, либо специализированным финансовым структурам - в активном продвижении соответствующих услуг. Анализа сущности этих принципиально новых форм финансового предпринимательства как экономических феноменов упомянутые работы не содержат.

В предлагаемой статье сделана попытка заполнить этот пробел и описать сущность лизинга, факторинга и форфейтинга с двух точек зрения: финансово-кредитной и экономикоорганизационной. Кроме того, представляет интерес выявление сходств и различий между этими инструментами.

Отдельно следует указать, что в данной статье вкладывается в понятие «современные формы финансового предпринимательства» вкладывается особый смысл. Безусловно, лизинг, факторинг и форфейтинг, с одной стороны, не являются абсолютно новыми для мировой практики и успешно применяются со второй половины прошлого века; а с другой стороны - этими инструментами все многообразие финансовых средств, появившихся в последние десятилетия, не исчерпывается. Поэтому прилагательное «современные» применяется для указания того, что анализируемые формы финансового

\footnotetext{
${ }^{22}$ Канд. эконом. наук, доцент кафедры экономики фирмы Санкт-Петербургского филиала Государственного университета - Высшей школы экономики.
} 
предпринимательства соответствуют современному состоянию рынка (которое можно описать как рынок покупателя) и современным развитым потребностям поставщиков и клиентов, нуждающихся не в унифицированных финансовых продуктах (каковыми являются банковские кредиты), а услугах, максимально адаптированных под их запросы (как это имеет место при лизинге, факторинге и форфейтинге).

Также следует уточнить, что термин «лизинг» (и соответственно «факторинг» и «форфейтинг») имеет в русском языке два значения:

- разновидность финансовой услуги (т.е. инструмент ведения бизнеса);

- вид деятельности, заключающийся в оказании соответствующей услуги (т.е. форма финансового предпринимательства).

Эти термины используются в тексте данной работы без уточнения значения в каждом конкретном случае.

\section{Предпосылки зарождения лизинга, факторинга и форфейтинга как особых форм финансового предпринимательства}

Хорошо известно, что между поставщиком и покупателем существует конфликт интересов в том, что касается условий сделки, и одним из видов такого конфликта является диаметрально противоположный подход к способу определения момента оплаты за поставленный товар. Поставщик стремится получить платеж в полном объеме как можно раньше, и желательно не позднее момента отгрузки, тогда как покупатель заинтересован в получении отсрочки платежа до того момента, пока он сам не получит прибыль от коммерческого использования купленного им у поставщика товара (т.е. пока не перепродаст его или изготовленную на его основе продукцию своим собственным клиентам и не получит от них полную оплату). Оплата по факту отгрузки товара поставщиком означает для покупателя изъятие собственных средств из оборота; разумеется, он желает избежать этого, а зачастую лишен возможности совершить такое изъятие из-за недостаточности средств. В этом случае при наличии достаточной заинтересованности покупателя или продавца в заключении сделки сторонами может быть выбран один из трех основных вариантов финансирования закупки товаров покупателем:

1. Банковский кредит в форме кредитования покупателя (который получает в банке недостающую для совершения покупки сумму).

2. Коммерческий кредит - сводится в конечном счете к отсрочке платежа за поставленный товар, предоставляемый поставщиком покупателю.

3. Смешанный кредит (малоизученный, но очень интересный с теоретической точки зрения способ финансирования) - экзотический по сути, но достаточно распространенный в современных условиях рынка покупателей вариант, когда у продавца отсутствует возможность предоставить коммерческий кредит из собственных средств, а покупатель по каким-либо причинам не может ни самостоятельно оплатить поставку, ни взять кредит в банке. В этом случае в банк за кредитом обращается продавец и за счет полученных средств предоставляет покупателю коммерческий кредит. Эта форма кредитования, как легко убедиться, представляет собой преобразование банковского кредита в коммерческий, совершаемый продавцом в интересах покупателя.

Каждый из этих способов кредитования обладает существенными недостатками.

При банковском кредитовании покупателя банк, по сути, за определенную плату (ссудный процент) продает денежные средства, которые выступают в качестве товара и (как и любой купленный товар) поступают в полное распоряжение заемщика. Получатель кредита расходует эти средства по своему усмотрению - в общем случае банк не имеет права влиять на решения заемщика по выбору направления их расходования. Недобросовестный заемщик вполне может использовать эти средства для покупки нового представительского автомобиля для директора, а не для приобретения новых основных фондов (такие прецеденты известны в 
практике российского бизнеса). Такое отсутствие контроля над заемщиком объективно повышает риски заимодавца. Далее, в своем решении о предоставлении кредита и о его условиях банка исходит из своего внутреннего регламента, а не от потребностей заемщика. Иными словами, заемщик должен своевременно вносить платежи по кредиту, независимо от того, получена ли прибыль от использования того товара, на приобретение которого был взят кредит.

Коммерческий кредит является эффективным инструментом стимулирования сбыта и наиболее удобен для покупателя. Как правило, ставка по нему ниже банковской, а в случае продажи товаров с малым сроком оборачиваемости (ТМСО) ставка может быть нулевой.

При закупке основных фондов с большим периодом отсрочки (от года и более) этот принцип не соблюдается, и покупатель должен выплачивать поставщику регулярные платежи.

По этим же причинам коммерческий кредит неудобен для поставщика. Он вынужден изымать собственные средства из оборота, что угрожает его финансовой стабильности. Кроме того, его функция - сбыт своих товаров, а не предоставление кредитов; выполнение непрофильной функции вынуждает его отвлекать организационные и людские ресурсы.

Наконец, смешанный кредит, для покупателя по условиям ничем не отличающийся от коммерческого, является самым неудобным для продавца. Если в случае коммерческого кредита продавец предоставлял его из собственных (квазибесплатных) средств, то при смешанном кредитовании он вынужден оплачивать банку использование его финансовых ресурсов, что снижает рентабельность сделки (особенно при продаже ТМСО, когда, как уже говорилось выше, поставщик применяет нулевую ставку коммерческого кредита). Кроме того, график платежей по банковскому кредиту никак не привязан к графику поступления платежей в счет поставки от покупателя.

Таким образом, традиционные формы кредитования оказываются неудобными как для банка, так и для продавца и покупателя.

Bсе вышеперечисленное означает, что банк в силу своей специализации и организационных особенностей не может обеспечить достижения ни одной из задач, нужных ему (владение объектом сделки при кредитовании покупателя), поставщику (проверка добросовестности покупателя при коммерческом кредитовании, выкуп его задолженности с дисконтом при коммерческом кредитовании и увязка графика платежей по банковскому и коммерческому кредитам при смешанном кредитовании) или покупателю (увязка графика платежей по кредиту с предпочтениями покупателя при банковском кредитовании). Однако потребность в решении этих задач есть.

Кроме того, отметим, что банки заинтересованы в повышении рентабельности своей деятельности, а за предоставление перечисленных выше услуг они вполне могли бы взимать комиссию (поскольку эти услуги являются для банка непрофильными и потому за их оказание должна взиматься отдельная плата).

Из перечисленных выше наблюдений естественным образом вытекает необходимость в независимых финансовых организациях, специализирующихся на оказании данных непрофильных услуг (включение этих услуг в свою линейку для банков нежелательно с организационной точки зрения). Эти организации, однако, должны быть аффилированы с банками (для обеспечения доступа к финансовым ресурсам, необходимым для оказания таких услуг). Ощущается потребность и в возникновении новых форм финансового предпринимательства (собственно, и состоящих в предоставлении описанных услуг):

1. Лизинг - приобретение на самостоятельно привлеченные средства основных фондов в интересах определенного пользователя у согласованного с этим пользователем поставщика и владение приобретенными основными фондами до их полной оплаты пользователем (т.е. кредитование лизингополучателя). Интересно отметить, что, хотя право собственности на приобретаемые основные фонды служит в конечном счете для защиты интересов аффилированного с лизингодателем банка, никакая комиссия за это с банка не взимается - все затраты несет лизингополучатель [Философова, 2008]. 
2. Факторинг - выкуп (с дисконтом) на самостоятельно привлеченные средства у поставщика краткосрочных прав требования к покупателю (как правило, в форме счетов за поставку), возникших вследствие продажи ТМСО, и проверка платежеспособности покупателя. При этом покупатель расплачивается с фактором в сроки, оговоренные с поставщиком (т.е. пользуется отсрочкой платежа), и не выплачивает ему ничего сверх стоимости поставки (доход фактора складывается исключительно из дисконта) [Бабичев, Лабзенко, Подлеснова, 2010].

3. Форфейтинг - выкуп (с дисконтом) на самостоятельно привлеченные средства среднесрочных долговых обязательств (векселей и тратт) покупателя перед поставщиком дорогостоящего оборудования и проверка платежеспособности покупателя. Как и в случае с факторингом, никакие дополнительные выплаты с покупателя не взимаются. Сроки выплат форфейтинговой компании совпадают со сроками, указанными в долговых обязательствах [Ачкасов, 1994].

Попытаемся проанализировать финансово-кредитное и экономико-организационное содержание этих форм финансового предпринимательства.

\section{Финансовое, экономическое и организационное содержание новых форм финансового предпринимательства}

Из приведенного выше описания лизинга, факторинга и форфейтинга явствует, что функции финансовых организаций, занимающихся оказанием этих услуг, радикально отличаются от функций банков. Банк, предоставив заемщику кредит, не контролирует его использование, и речь идет о двух независимых, не связанных друг с другом сделках:

1. Банк кредитует заемщика.

2. Заемщик либо приобретает товар у поставщика (при банковском кредитовании покупателя), либо предоставляет покупателю коммерческий кредит (при смешанном кредитовании).

При новых формах финансового предпринимательства оказывающая соответствующие услуги финансовая структура становится не просто поставщиком денег одной из сторон сделки купли-продажи, а полноправным участником сделки между поставщиком и покупателем: при лизинге лизингодатель приобретает объект лизинга у поставщика, а при факторинге и форфейтинге фактор и форфейтинговая компания взыскивают сумму задолженности не со своего клиента (поставщика), а с покупателя, и принимают на себя риск неоплаты. Таким образом, на смену двум независимым двусторонним сделкам приходит одна трехсторонняя сделка «поставщик - финансовая структура - покупатель», в которой финансовые взаимоотношения между поставщиком и покупателем осуществляются не напрямую, а через посредство финансовой структуры. Такую форму финансирования сделки можно назвать посреднической. Задача финансового посредника - согласовать интересы поставщика и покупателя, у которых отсутствуют собственные свободные финансовые ресурсы и по каким-либо причинам нет возможности обратиться за традиционным банковским кредитом. Именно такова организационная сущность этих форм ведения бизнеса - согласование финансовых интересов поставщика и покупателя через посредство специализированной финансовой организации.

Рассмотрим подробнее все три перечисленные выше инструмента ведения бизнеса.

В случае лизинга лизингодатель [Философова, 2008] привлекает заемные ресурсы для приобретения нужного лизингополучателю оборудования. Затем в течение срока действия договора лизинга лизингополучатель поэтапно возмещает лизингодателю его затраты с возможным последующим переходом оборудования в собственность лизингополучателя (или, точнее, поэтапно возмещает лизингодателю заранее оговоренную долю от стоимости оборудования, после чего оно по остаточной стоимости либо переходит к лизингополучателю, либо остается в распоряжении лизингодателя). Легко убедиться, что возмещение этой доли происходит на условиях коммерческого кредита. 
При факторинге и форфейтинге [Ачкасов, 1994; Бабичев, Лабзенко, Подлеснова, 2010] финансовая компания привлекает заемные (банковские) средства для выкупа у поставщика обязательств покупателя перед ним. Впоследствии поставщик расплачивается с финансовой компанией. По сути дела, поставщик переуступает финансовой компании права требования по предоставленному покупателю коммерческому кредиту.

Итак, при использовании всех трех новых форм финансового предпринимательства финансовая компания сначала на условиях банковского кредитования привлекает денежные средства для финансирования единовременной выплаты поставщику стоимости проданного товара, а затем получает в счет компенсации своих затрат выплаты от покупателя (в случае лизинга - предоставляет лизингополучателю коммерческий кредит, в случае факторинга и форфейтинга - получает в отношении покупателя права требования по коммерческому кредиту). Это позволяет сделать вывод о том, что перечисленные формы финансового предпринимательства представляют собой преобразование финансовым посредником банковского кредита в коммерческий в интересах поставщика и покупателя. Именно такова, на наш взгляд, финансово-кредитная сущность лизинга, факторинга и форфейтинга. Важным отличием лизинга от факторинга и форфейтинга является то, что он предполагает, что владеет объектом сделки лизингодатель, тогда как при факторинге и форфейтинге права собственности на объект сделки переходят к покупателю.

Что же касается экономической сущности этих явлений, то отметим следующее.

1. При лизинге лизингодатель аккумулирует в интересах лизингополучателя, но по своему усмотрению и из своих источников, средства для оплаты покупки нужного лизингополучателю оборудования, а затем владеет объектом лизинга в течение всего срока действия договора. За свои услуги лизингодатель получает от лизингодателя плату в виде комиссионных, включаемых в лизинговые платежи. При этом приобретается указанное лизингополучателем оборудование у указанного лизингополучателем поставщика. Иными словами, лизингополучатель передает лизингодателю функции финансирования покупки объекта лизинга и владения им, т.е. лизингодатель сначала привлекает в интересах лизингополучателя капитал в денежной форме, а затем предоставляет ему в пользование капитал в физической форме (оборудование).

2. При факторинге и форфейтинге финансовая структура аккумулирует заемный капитал в интересах поставщика для единовременной оплаты стоимости продаваемого покупателю товара. За эту услугу финансовая структура получает от поставщика плату в виде дисконта от стоимости переданных ему прав требования. Таким образом, поставщик передает финансовой структуре функцию взимания платежа за поставленный товар с покупателя (и шире - функцию финансовых отношений с покупателем, так как финансовая структура должна провести проверку его платежеспособности и т.д.).

Все вышесказанное позволяет утверждать, что в случае лизинга, факторинга и форфейтинга мы имеем дело с аутсорсингом капитала. При лизинге речь идет об аутсорсинге капитала в денежной и физической форме в интересах лизингополучателя (покупателя), а при факторинге и форфейтинге - об аутсорсинге капитала в денежной форме в интересах поставщика. Речь идет не о кредите или займе, а именно об аутсорсинге капитала, так как отношения оператора (соответственно, лизингодателя, фактора и форфейтинговой компании) и заказчика (лизингополучателя при лизинге, поставщика при факторинге и форфейтинге) удовлетворяют требованиям, предъявляемым к аутсорсингу [Аникин, Рудая, 2009; Карашевич 2008; Кремлева 2009]. В частности, характеристики услуги (сумма сделки, размеры и график платежей, в случае лизинга - объект сделки) полностью адаптированы под требования заказчика, а не являются стандартизированными; к тому же в течение периода действия договора оператор фактически выступает внешним независимым подразделением заказчика, полностью беря на себя соответствующую функцию (при лизинге - покупку и владение объектом лизинга, при факторинге и форфейтинге - финансовые отношения с 
покупателями).

Все эти утверждения систематизированы в виде таблицы.

Содержание лизинга, факторинга и форфейтинга

\begin{tabular}{|c|c|c|c|}
\hline & Лизинг & Факторинг & Форфейтинг \\
\hline $\begin{array}{l}\text { Организационная } \\
\text { сущность }\end{array}$ & $\begin{array}{l}\text { Посредническое } \\
\text { финансирование } \\
\text { (купли/продажи } \\
\text { основных фондов) }\end{array}$ & $\begin{array}{l}\text { Посредническое } \\
\text { финансирование } \\
\text { (купли/продажи } \\
\text { товаров с малым } \\
\text { сроком } \\
\text { оборачиваемости) }\end{array}$ & $\begin{array}{l}\text { Посредническое } \\
\text { финансирование } \\
\text { (купли/продажи } \\
\text { дорогостоящих и } \\
\text { уникальных } \\
\text { основных фондов) }\end{array}$ \\
\hline $\begin{array}{l}\text { Финансово- } \\
\text { кредитная } \\
\text { сущность }\end{array}$ & $\begin{array}{l}\text { Преобразование } \\
\text { банковского кредита } \\
\text { в коммерческий в } \\
\text { интересах } \\
\text { лизингодателя и } \\
\text { поставщика с } \\
\text { получением прав } \\
\text { собственности на } \\
\text { объект лизинга }\end{array}$ & $\begin{array}{l}\text { Преобразование } \\
\text { банковского кредита } \\
\text { в коммерческий в } \\
\text { интересах } \\
\text { поставщика и } \\
\text { покупателя }\end{array}$ & $\begin{array}{l}\text { Преобразование } \\
\text { банковского кредита } \\
\text { в коммерческий в } \\
\text { интересах } \\
\text { поставщика и } \\
\text { покупателя }\end{array}$ \\
\hline $\begin{array}{l}\text { Экономическая } \\
\text { сущность }\end{array}$ & $\begin{array}{l}\text { Аутсорсинг } \\
\text { капитала в } \\
\text { физической и } \\
\text { денежной форме в } \\
\text { интересах } \\
\text { лизингополучателя }\end{array}$ & $\begin{array}{l}\text { Аутсорсинг капитала } \\
\text { в денежной форме в } \\
\text { интересах } \\
\text { поставщика }\end{array}$ & $\begin{array}{l}\text { Аутсорсинг капитала } \\
\text { в денежной форме в } \\
\text { интересах } \\
\text { поставщика }\end{array}$ \\
\hline
\end{tabular}

Основные характеристики лизинга, факторинга и форфейтинга

Основные характеристики изучаемых форм финансового предпринимательства представлены также в виде таблицы.

Таблица 2

Характеристики новых форм финансового предпринимательства

\begin{tabular}{|l|l|l|l|}
\hline \multicolumn{1}{|c|}{ Характеристика } & \multicolumn{1}{|c|}{ Лизинг } & \multicolumn{1}{|c|}{ Факторинг } & \multicolumn{1}{|c|}{ Форфейтинг } \\
\hline $\begin{array}{l}\text { Продолжительность } \\
\text { финансирования }\end{array}$ & $\begin{array}{l}\text { Средне- и } \\
\text { долгосрочное }\end{array}$ & $\begin{array}{l}\text { Краткосрочное } \\
\text { долгосрочное }\end{array}$ \\
\hline Объект сделки & Основные фонды & $\begin{array}{l}\text { Дебиторская } \\
\text { задолженность }\end{array}$ & $\begin{array}{l}\text { Долговые } \\
\text { обязательства } \\
\text { покупателя }\end{array}$ \\
\hline $\begin{array}{l}\text { Товар, покупаемый } \\
\text { в ходе сделки }\end{array}$ & Основные фонды & $\begin{array}{l}\text { Товары с малым } \\
\text { сроком } \\
\text { оборачиваемости }\end{array}$ & $\begin{array}{l}\text { Основные фонды } \\
\text { (дорогостоящие или } \\
\text { уникальные) }\end{array}$ \\
\hline $\begin{array}{l}\text { Оператор } \\
\text { (организация, } \\
\text { финансирующая } \\
\text { сделку) }\end{array}$ & Лизингодатель & $\begin{array}{l}\text { Фактор } \\
\text { Горфейтинговая } \\
\text { Гарантии оператора }\end{array}$ & $\begin{array}{l}\text { Право } \\
\text { собственности на }\end{array}$ \\
\hline
\end{tabular}




\begin{tabular}{|l|l|l|l|}
\hline & объект лизинга & поставщика & $\begin{array}{l}\text { могут привлекаться } \\
\text { банковские гарантии } \\
\text { и поручительства } \\
\text { [Ачкасов 1994] }\end{array}$ \\
\hline $\begin{array}{l}\text { Число сторон в } \\
\text { сделке }\end{array}$ & $\begin{array}{l}\text { Три (поставщик, } \\
\text { лизингодатель, } \\
\text { лизингополучатель) }\end{array}$ & $\begin{array}{l}\text { Три (поставщик, } \\
\text { фактор, покупатель) }\end{array}$ & $\begin{array}{l}\text { Три (поставщик, } \\
\text { форфейтинговая } \\
\text { компания, } \\
\text { покупатель) }\end{array}$ \\
\hline $\begin{array}{l}\text { Сторона, } \\
\text { оплачивающая } \\
\text { услуги оператора }\end{array}$ & $\begin{array}{l}\text { Лизингополучатель } \\
\text { Возможность } \\
\text { регресса на } \\
\text { поставщика }\end{array}$ & $\begin{array}{l}\text { Поставщик } \\
\text { (противоречит самой }\end{array}$ & $\begin{array}{l}\text { Возможен (но } \\
\text { необязателен) }\end{array}$ \\
$\begin{array}{l}\text { природе сделки, так } \\
\text { как право } \\
\text { собственности на } \\
\text { объект лизинга } \\
\text { переходит к } \\
\text { оператору) }\end{array}$ & Запрещен \\
\hline
\end{tabular}

Отметим, что у этих трех форм финансового предпринимательства можно выявить и другие характеристики, однако здесь приведены только основные.

Также небезынтересно проанализировать риски, связанные с использованием соответствующего инструмента ведения бизнеса. Речь пойдет в первую очередь о рисках компаний-операторов, предоставляющих соответствующие услуги, так как они не только принимают на себя существенную часть рисков поставщиков, связанных с предоставлением отсрочки платежа, но также несут и собственные специфические риски. Иными словами, за одним исключением, которое будет рассмотрено ниже, риски поставщика при использовании данных инструментов меньше, чем при прямой работе с клиентами с предоставлением им отсрочки, - благодаря тому, что часть рисков передается финансовому аутсорсеру. Перечень основных рисков оператора приведен в таблице 3.

Таблица 3

Риски компаний, предлагающих услуги лизинга, факторинга и форфейтинга

\begin{tabular}{|c|c|c|c|c|}
\hline Тип риска & Сущность риска & Лизингодатель & Фактор & Форфейтер \\
\hline \multicolumn{5}{|c|}{ Риски поставщика, принимаемые на себя оператором } \\
\hline $\begin{array}{l}\text { Риск } \\
\text { ликвидности }\end{array}$ & $\begin{array}{l}\text { Отказ покупателя } \\
\text { своевременно } \\
\text { производить } \\
\text { оплату } \\
\begin{array}{l}\text { поставленный } \\
\text { товар }\end{array}\end{array}$ & Принимает на себя & $\begin{array}{l}\text { Принимает } \\
\text { на себя } \\
\text { (возможен } \\
\text { регресс на } \\
\text { поставщика) }\end{array}$ & $\begin{array}{l}\text { Принимает на } \\
\text { себя (как правило, } \\
\text { требует гарантии } \\
\text { от } \\
\text { импортера) }\end{array}$ \\
\hline $\begin{array}{l}\text { Кредитный } \\
\text { риск }\end{array}$ & $\begin{array}{l}\text { Невозможность } \\
\text { для покупателя в } \\
\text { принципе } \\
\text { оплачивать } \\
\text { приобретенный } \\
\text { товар }\end{array}$ & $\begin{array}{l}\text { Принимает на себя } \\
\text { (в обеспечение } \\
\text { обязательств } \\
\text { лизингополучателя } \\
\text { может изъять } \\
\text { объект лизинга) }\end{array}$ & $\begin{array}{l}\text { Принимает } \\
\text { на себя } \\
\text { (возможен } \\
\text { регресс на } \\
\text { поставщика) }\end{array}$ & $\begin{array}{lr}\text { Принимает } \\
\text { себя (как правило, } \\
\text { требует гарантии } \\
\text { от } \\
\text { импортера) }\end{array}$ \\
\hline $\begin{array}{l}\text { Валютный риск } \\
\text { (при } \\
\text { международных }\end{array}$ & $\begin{array}{l}\text { Неблагоприятные } \\
\text { колебания курса } \\
\text { валют }\end{array}$ & Принимает на себя & $\begin{array}{l}\text { Принимает } \\
\text { на себя }\end{array}$ & $\begin{array}{l}\text { Принимает } \\
\text { себя }\end{array}$ \\
\hline
\end{tabular}




\begin{tabular}{|c|c|c|c|c|}
\hline сделках) & & & & \\
\hline \multicolumn{5}{|c|}{ Специфические риски оператора } \\
\hline $\begin{array}{l}\text { Риск } \\
\text { удорожания } \\
\text { кредитных } \\
\text { ресурсов }\end{array}$ & 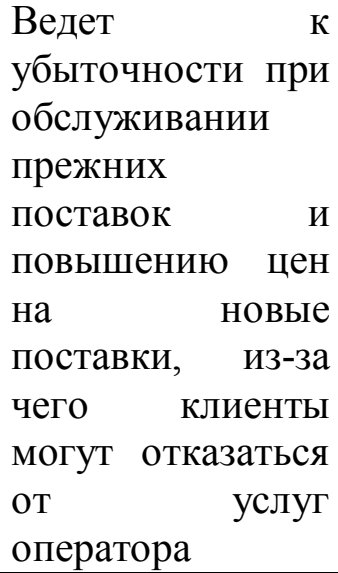 & Велик & Велик & Велик \\
\hline $\begin{array}{l}\text { Отказ } \\
\text { поставщиков от } \\
\text { предоставления } \\
\text { отсрочки } \\
\text { платежа }\end{array}$ & $\begin{array}{l}\text { Устраняет } \\
\text { необходимость в } \\
\text { услугах } \\
\text { операторов }\end{array}$ & $\begin{array}{l}\text { Не } \quad \text { играет } \\
\text { существенной } \\
\text { роли }\end{array}$ & Велик & $\begin{array}{l}\text { Наступление } \\
\text { данного риска } \\
\text { маловероятно, так } \\
\text { как форфейтеры } \\
\text { обслуживают } \\
\text { дорогостоящие } \\
\text { поставки } \\
\text { уникальных } \\
\text { товаров, } \\
\text { единовременная } \\
\text { оплата которых } \\
\text { для покупателей } \\
\text { невозможна } \\
\text { (т.е. поставщики } \\
\text { вынуждены } \\
\text { предоставлять } \\
\text { отсрочку платежа) }\end{array}$ \\
\hline
\end{tabular}

Единственным примером увеличения риска поставщика при использовании услуг финансового оператора является риск неоплаты счетов покупателем при факторинге с регрессом. В этом случае издержки поставщика существенно увеличиваются за счет дополнительных штрафов и комиссий, взимаемых с него фактором.

Интересно отметить, что торможение российского рынка лизинга и факторинга (форфейтинг пока является в России достаточно экзотическим продуктом), имевшее место в ходе экономического кризиса 2008-2009 годов, было обусловлено не столько усилением рисков поставщика, принимаемых на себя оператором (хотя рост просрочки платежей и имел место), сколько наступлением рисков, типичных для собственно операторской деятельности. Рост стоимости кредитов, связанный с увеличением кредитных рисков банков, вынудил лизингодателей и факторов повышать стоимость своих услуг, что оттолкнуло от них их традиционных клиентов. В свою очередь, нежелание поставщиков товаров массового спроса предоставлять в условиях кризиса своим традиционным клиентам отсрочку платежа (из-за усиления потребности в ликвидности) во многом подкосило факторинговый бизнес.

\section{Выводы}

Выполненный в работе анализ позволил, по мнению автора, уточнить финансовокредитное, экономическое и организационное содержание таких важных и становящихся все более популярных форм финансового предпринимательства, как лизинг, факторинг и 
форфейтинг. На наш взгляд, особый интерес представляет выявление у них аутсорсинговой составляющей. Также важно понимать то, что в каждой из соответствующих сделок задействованы не две, а три стороны - если в случае лизинга на это указывается однозначно, то в случае факторинга и форфейтинга внимание на этом не акцентируется, вследствие чего природа этих форм предпринимательства (и соответствующих сделок) несколько затемняется.

Автор надеется, что полученные им результаты окажутся полезными как для исследователей лизинга, факторинга и форфейтинга, так и для практиков, применяющих эти инструменты в своей хозяйственной деятельности.

\section{Список литературы}

1. Аникин Б.А., Рудая И.Л. Аутсорсинг и аутстаффинг: высокие технологии менеджмента. М.: ИНФРА-М, 2009.

2. Ачкасов А.И. Операции «а-форфэ». Общая характеристика и техника совершения. М.: Издательство АО «Консалтбанкир», 1994.

3. Бабичев С.Н., Лабзенко А.А., Подлеснова А.Ю. Факторинг. М.: Маркет ДС, 2010.

4. Карашевич В.Е. От подряда к аутсорсингу - первые шаги // Инновации. 2008. № 1 (111). С. 125-128.

5. Кирилловых А.А. Правовые основы лизинга: учеб.-практ. пособие. М.: Юстицинформ, 2009.

6. Кремлева Н.А. Обеспечение конкурентных преимуществ производства и реализации продукции на основе аутсорсинговой модели организации бизнеса предприятия // Организатор производства. 2009. № 43. С. 72-75.

7. Философова Т.Г. Лизинг. М.: Юнити-Дана, 2008. 